\title{
Türkiye'den oribatid akarların(Acari) iki yeni kaydı: Cepheus caucasicus Sitnikova, 1975 ve Lopheremaeus laminipes (Berlese, 1916) ${ }^{1}$
}

\author{
$\underline{\text { Sedat PER }}^{2} \quad$ Ayşe TOLUK ${ }^{3} \quad$ Kübra DENLí ${ }^{4} \quad$ Nusret AYYILDIZ $^{3}$
}

\begin{abstract}
Two new records of oribatid mites (Acari) from Turkey: Cepheus caucasicus Sitnikova, 1975 and Lopheremaeus laminipes (Berlese, 1916)

In this study, on the basis of the specimens collected from Yozgat and Sakarya provinces Cepheus caucasicus Sitnikova, 1975 and Lopheremaeus laminipes (Berlese, 1916) were recorded for the first time from Turkey. Their morphological features were given with the scanning electron microscope images.
\end{abstract}

Keywords: Oribatid mites, Cepheidae, Plateremaeidae, new records, Turkey

\section{$\ddot{O} \mathbf{Z}$}

$\mathrm{Bu}$ çalışmada, Yozgat ve Sakarya illerinden toplanan örneklere dayanarak Cepheus caucasicus Sitnikova, 1975 ve Lopheremaeus laminipes (Berlese, 1916) Türkiye'den ilk defa kaydedilmiştir. Morfolojik özellikleri tarama elektron mikroskobu görüntüleri ile birlikte verilmiştir.

Anahtar kelimeler: Oribatid akarlar, Cepheidae, Plateremaeidae, yeni kayıtlar, Türkiye

\section{GİRIŞ}

Oribatid akarlar, toprakta yaşayan eklembacaklılar arasında sayıca en baskın gruplardan birini temsil etmekte olup, toprak içerisinde organik maddelerin ayrışmasında ve mikroorganizmaların dağılımında önemli rol oynamaktadır.

\footnotetext{
${ }^{1}$ Bu çalışma, 23-27 Mayıs 2016 tarihinde Antalya'da düzenlenen Symposium on EuroAsian Biodiversity (SEAB-2016)'da poster bildiri olarak sunulmuş ve özet olarak basılmıştır.

${ }^{2}$ Bozok Üniversitesi, Fen - Edebiyat Fakültesi, Biyoloji Bölümü, Yozgat

${ }^{3}$ Erciyes Üniversitesi, Fen Fakültesi, Biyoloji Bölümü, Kayseri

${ }^{4}$ Bozok Üniversitesi, Fen Bilimleri Enstitüsü, Biyoloji Anabilim Dalı, Yozgat Sorumlu yazar (Corresponding author) e-mail: sedat.per@bozok.edu.tr Alınış (Received): 29.07.2016, Kabul ediliş (Accepted): 02.11.2016
} 
Türkiye'den oribatid akarların(Acari) iki yeni kaydı: Cepheus caucasicus Sitnikova, 1975 ve Lopheremaeus laminipes (Berlese, 1916)

(Wissuwa et al. 2013). Şimdiye kadar tanımı yapılmış oribatid akarların tür ve türaltı takson sayısı 10.826 olarak belirlenmiştir (Subías 2004).

Cepheus Koch, 1835; geniş lamellaları, uzun interlamella kılları, düz ve kısa 10 çift notogaster kılı, geniş tuberküllü humeral bölgesi, altı çift genital kılı ve bacaklarının birer tırnaklı olması ile karakterize edilir (Ayyıldız et al. 2011). Yarı kozmopolit bir yayılıș gösteren bu cins, dünyada şimdilik 27 tür ile temsil edilmektedir (Subias 2004). Ülkemizden şimdiye kadar bu cinse ait sadece $C$. dentatus (Michael, 1888) kaydedilmiştir (Ayyıldız et al. 2011).

Lopheremaeus Paschoal, 1987; vücut ve bacakların yüzeyinin dorsal ve ventralde çukurcuklara sahip olması, sensilluslarının uzun ve uçta çok kısa diken taşıması, epimer bölgesi kıllarının dağılımı 8:7:12:4(?) şeklinde olması, genito-anal kıl formülünün 7-1-4-3 şeklinde olması ve femurların dorsal ve ventralde iyi gelişmiş tepeciklere sahip olması ile karakterize edilir (Paschoal 1986). Türkiye'den daha önce bu cinse ait herhangi bir tür kaydına rastlanılmamıştır (Erman et al. 2007).

$\mathrm{Bu}$ çalışmada, Türkiye oribatid akar faunasına katk1 sağlamak amacıyla Karanlıkdere Vadisi (Yozgat) ve Kılıçkaya Tepesi (Sakarya) bölgelerinden toplanan akar örneklerinin değerlendirilmesi sonucunda Türkiye faunası için yeni kayit olarak belirlenen Cepheus caucasicus Sitnikova, 1975 ve Lopheremaeus laminipes (Berlese, 1916) türlerinin tarama elektron mikroskobu incelemelerine dayanarak tanımları ve dünyadaki yayılışları verilmiştir.

\section{MATERYAL VE METOT}

Çalışma materyali; 2014 yılında Karanlıkdere Vadisi'nden (Yozgat) ve 2015 y1lında Kılıçkaya Tepesinden (Sakarya) toplanan toprak örneklerinden Berlese hunileri kullanılarak seçilen oribatid akarlar olușturmaktadır. Oribatid akarların mikroskobik incelemeleri CX21 model Olympus 1ș1k mikroskobunda gliserinli veya 1:2 oranındaki su-laktik asit ortamında gerçekleştirilmiştir. Ayrıca, gerektiğinde Hoyer ortamında geçici preparatları yapılmıştır. Teşhisi yapılan örneklerin taramalı elektron mikroskobunda incelemeleri ise Erciyes Üniversitesi, Teknoloji Araştırma ve Uygulama Merkezi'nde yapılmıştır. İncelenmesi tamamlanan örnekler etiketlenerek, Bozok Üniversitesi, Fen-Edebiyat Fakültesi, Biyoloji Bölümü Akaroloji koleksiyonunda muhafaza altına alınmıştır.

\section{SONUÇLAR}

Üst familya: Eutegaeoidae Balogh, 1965

Familya: Compactozetidae Luxton, 1988

Cins: Cepheus Koch, 1835

Tür: Cepheus caucasicus Sitnikova, 1975

Ölçümler: Vücut uzunluğu ortalama 775 (750-800) $\mu$ m; genişliği ise ortalama 520 (500-540) $\mu$ m'dir $(\mathrm{n}=4)$. 
Prodorsum: Vücut, koyu kahverengi renktedir. Rostrum yuvarlak, rostrum kılları ortalama $60 \mu \mathrm{m}$ uzunluğunda ve seyrek dikenlidir. Lamellalar, boylu boyunca ayn genişlikte olup rostruma kadar uzanmaktadır. Lamella kılları ortalama $85 \mu \mathrm{m}$ uzunluğunda, güçlü ve bir taraflı seyrek dikenlidir. İnterlamella kılları ortalama $145 \mu$ m uzunluğunda ve lamella kıllarının ortasına kadar uzanmakta olup güçlü ve bir taraflı dikenlidir. Sensillus çomak şeklinde, yüzeyi pullu ve $\mathrm{S}$ şeklinde konumlanmış olup sap kısmı ortalama $40 \mu \mathrm{m}$, baş kısmı ise ortalama $25 \mu \mathrm{m}$ uzunluğundadır (Şekil $1 \mathrm{~A}-\mathrm{C}$ ).

Notogaster: Yüzeyi çokgen şeklinde ağsı yapıda kalın bir kerotegüment tabakası ile örtülüdür. Dorsosejugal sutur ortada biraz düz şekilde ve her bir yanda humeral çıkıntı vardır. Notogaster ortalama $590 \mu \mathrm{m}$ uzunluğundadır. On çift yay şeklinde ve dikenli kıl taşır. Altı çift notogaster kılı yukardan aşağı kenardan merkeze doğru yerleşmiştir ve uzunlukları 45-80 $\mu \mathrm{m}$ arasında değişmektedir. $c_{3}$ k1lı humeral çıkıntının üzerinden çıkmaktadır. $p$ serisi kıllar notogasterin arka kenarına yerleşmiştir ve uzunlukları 20-30 $\mu \mathrm{m}$ arasında değişmektedir (Şekil 1 A, D).

Karın Bölgesi: Epimer kılları düz, farklı uzunlukta ve dağılımı 3-1-3-3 şeklindedir. Genital plak ortalama $105 \mu \mathrm{m}$ uzunluğunda ve $85 \mu \mathrm{m}$ genişliğindedir; yaklaşık olarak aynı sırada yerleşmiş altı çift kısa ve düz kıl taşır. Genital ve anal plaklar arası mesafe ortalama $50 \mu \mathrm{m}$ kadardır. Anal plak ortalama $135 \mu \mathrm{m}$ uzunluğunda ve $120 \mu \mathrm{m}$ genişliğindedir; iki çift kıl taşımaktadır (Şekil $1 \mathrm{E}, \mathrm{F}$ ).

Bacaklar: Bir tırnaklıdır (Şekil 1 D, E).

İncelenen materyal: Sakarya: Geyve. K1lı̧̧kaya tepesi, $40^{\circ} 28.800^{\prime} \mathrm{K}, 30^{\circ} 27.930^{\prime}$ D, 1100 m, 13 Haziran 2015, çam (Pinus sp.) altı döküntü ve toprak, 2 örnek; $40^{\circ}$ $30.129^{\prime} \mathrm{K}, 30^{\circ} 28.348^{\prime} \mathrm{D}, 1288 \mathrm{~m}, 19$ Haziran 2015, göknar (Abies sp.) altı döküntü ve toprak, 2 örnek (örnekler SEM çalışmasında kullanılmıştır). 
Türkiye'den oribatid akarların(Acari) iki yeni kaydı: Cepheus caucasicus Sitnikova, 1975 ve Lopheremaeus laminipes (Berlese, 1916)
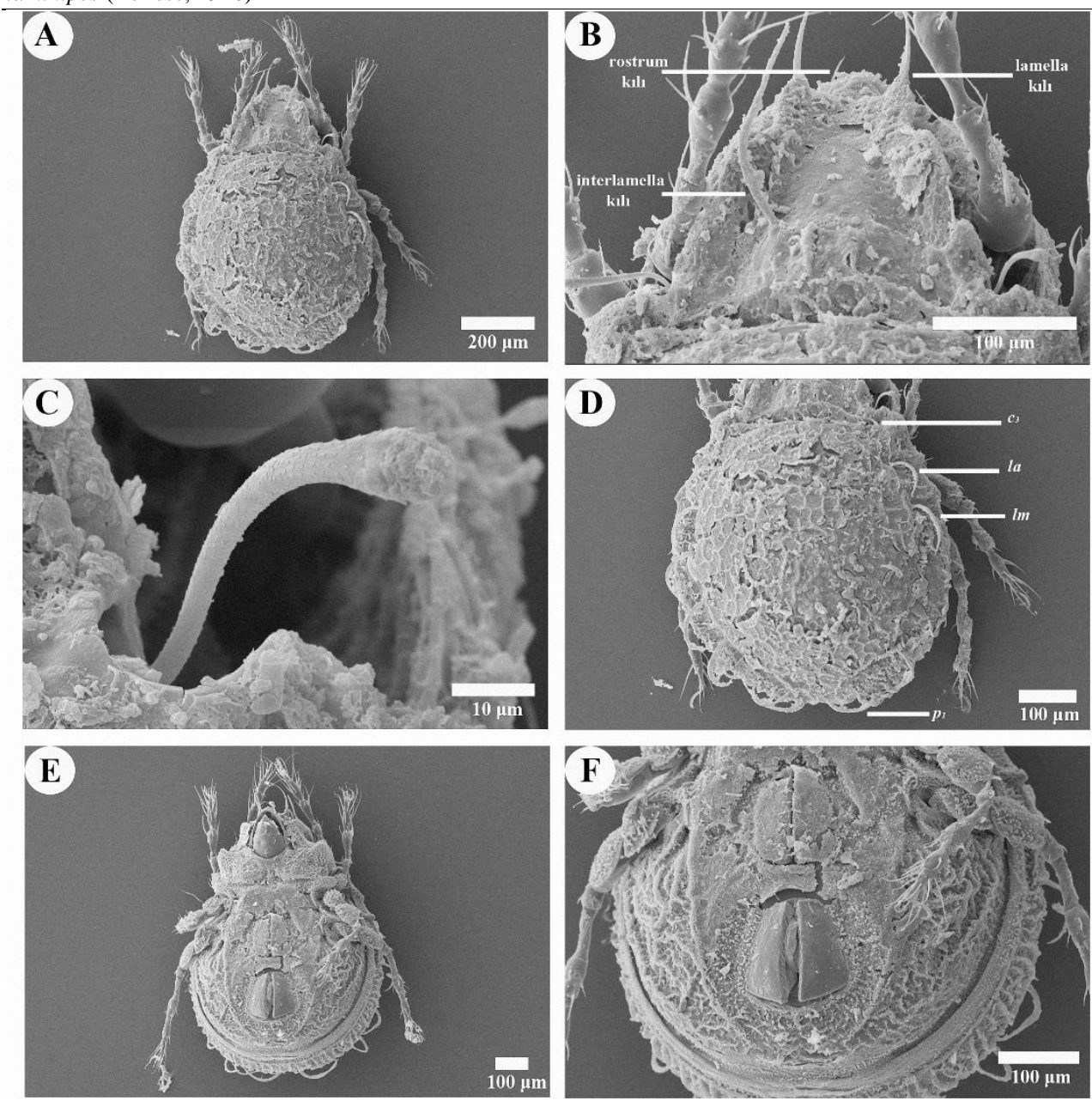

Şekil 1. Cepheus caucasicus Sitnikova, 1975. A- Vücut sırttan, B- Prodorsum, CSensillus, D- Notogaster, E- Vücut karından, F- Genito-anal bölge.

Üst familya: Plateremaeoidae Trägårdh, 1926

Familya: Plateremaeidae Trägårdh, 1926

Cins: Lopheremaeus Paschoal, 1987

Tür: Lopheremaeus laminipes (Berlese, 1916)

Ölçümler: Vücut uzunluğu ortalama $425(400-450) \mu \mathrm{m}$; genişliği ise ortalama 220 (210-230) $\mu m^{\prime} \operatorname{dir}(\mathrm{n}=6)$.

Prodorsum: Rostrum yuvarlak, rostrum kılları ortalama $35 \mu \mathrm{m}$ uzunlukta olup, ön kenarda lamella kılları ile birbirine yakın olarak yerleşmiştir. İnterlamella kılları çok kısadır. Sensillus ortalama $100 \mu \mathrm{m}$ uzunluğunda olup kısa bir dirsek yaptıktan sonra uzun ve uçta kıvrılmış kamçı şeklindedir. 
Notogaster: Çokgen şeklinde ağsı görünümde çukurluklu desene sahiptir. Notogaster ortalama $300 \mu \mathrm{m}$ uzunluğunda ve $220 \mu \mathrm{m}$ genişliğindedir. Notogaster kıllarından sadece arka üç çift kenar kılı ayırt edilmektedir. Bu kıllar ince ve düzdür.

Karın Bölgesi: Subkapitulum iki eklemlidir. $m$ ve $h$ kılları uzun, kamçı şeklinde ve bir taraflı sillidir. $a$ kılları $m$ ve $h$ kılları gibi aynı yapıda olup bunların 1/3'ü kadar uzunluktadır. Epimeral kıllardan, I. epimer bölgesinin ön kenarında bulunan üç çift kı1 diğer epimeral kılların üç katı kadar $(30 \mu \mathrm{m})$ uzunluktadır. Epimeral bölgede ikincil kıllanma mevcuttur. Kılların dağılımı 7-7-9-10 şeklindedir. Genital plak ortalama $70 \mu \mathrm{m}$ uzunluğunda ve $60 \mu \mathrm{m}$ genişliğindedir; $4+3$ şeklinde yerleşmiş toplam yedi çift kıl taşır. Anal plak ortalama $100 \mu \mathrm{m}$ uzunluğunda ve $75 \mu \mathrm{m}$ genişliğindedir; dört çift basit ve kıvrık kı1 taşımaktadır. Üç çift adanal kıl mevcuttur (Şekil 2 ).

Bacaklar: Üç tırnaklıdır (Şekil 2 B).

İncelenen materyal: Yozgat: Şefaatli-Yerköy. Karanlıkdere vadisi, 39³ 30.184' K, $34^{\circ}$ 44.533' D, 908 m, 23 Mayıs 2014, iğde (Elaeagnus sp.) altı döküntü ve toprak, 3 örnek; 39 30.184' K, 34 44.533' D, 908 m, 23 May1s 2014, ayva (Cydonia sp.) altı döküntü ve toprak, 2 örnek; 39 34.809' K, 34 35.678' D, 813 m, 06 Haziran 2014, toprak, 1 örnek; (örnek SEM çalışmasında kullanılmıştır).
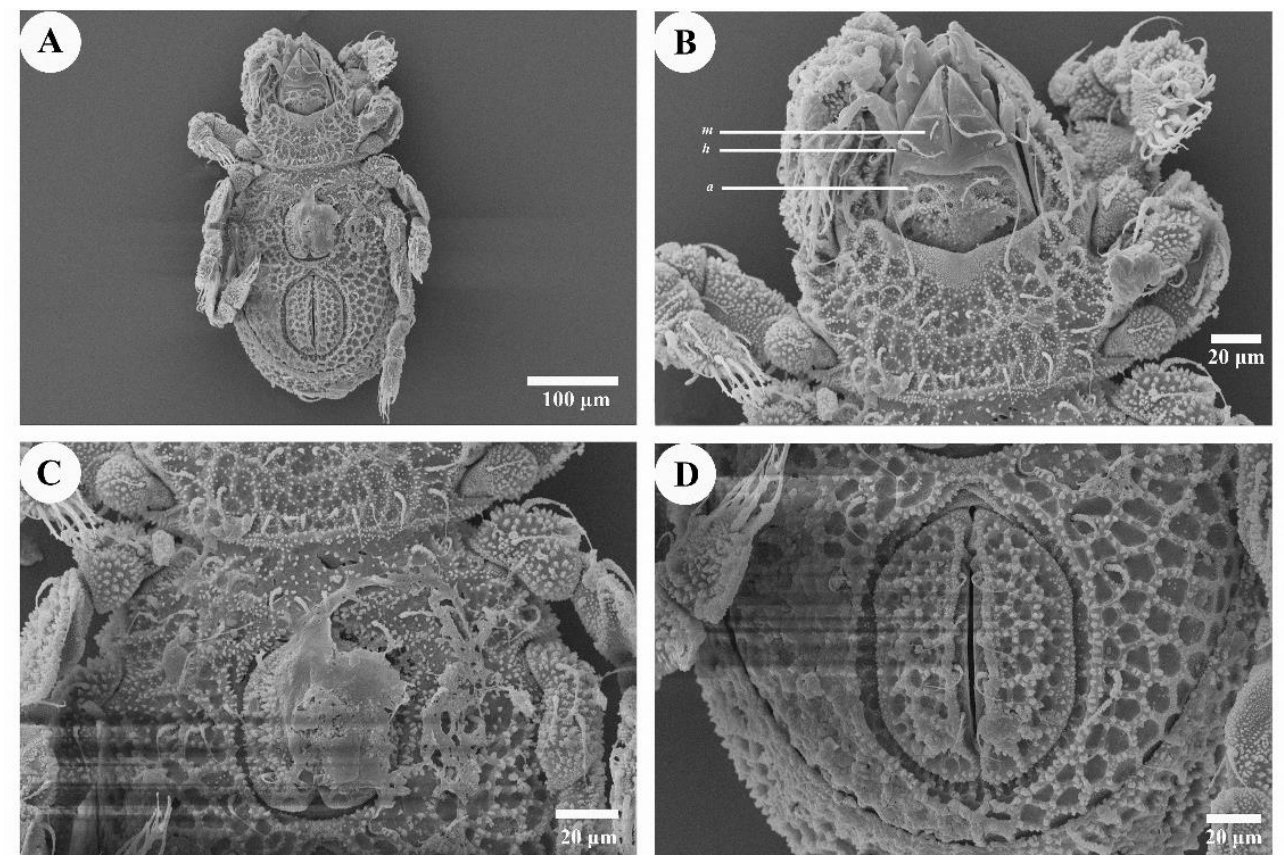

Şekil 2. Lopheremaeus laminipes (Berlese, 1916). A- Vücut karından, B- İnfrakapitulum, C- Genital bölge, D- Anal plak. 


\section{TARTIŞMA VE KANI}

Cepheus caucasicus Sitnikova, 1975; Kafkasya'da bilinmekte olup, Türkiye'den ilk defa kaydedilmiştir. Bu tür; 758/550 $\mu \mathrm{m}$ büyüklüğünde, lamellaların geniş, interlamella kıllarının uzun, notogasterin kısa ve düz on çift kıl taşıması, humeral bölgenin belirgin halde çıkıntılı olması, altı çift genital kıl taşıması ve bacaklarının bir tırnaklı olması ile ayırt edilir (Sitnikova 1975). İncelediğimiz örneklerde notogaster kıllarının kısa dikenli olması ile bilinen özelliklerden ayrılmaktadır. Bu farklılığın tarama elektron mikroskobu inceleme yönteminden kaynaklandığı kanısındayız. Örneklerimizde vücut büyüklügü $775 / 520 \mu \mathrm{m}$ olarak ölçülmüş olup türün bilinen ölçüm değerleri ile tam bir uyum içerisindedir.

Lopheremaeus laminipes (Berlese, 1916); Avrupa'da bilinmekte olup, Türkiye'den ilk defa kaydedilmiştir. Bu tür; Plateremaeus mirabilis tip türü ile Lopheremaeus cinsi oluşturulurken yeni kombinasyon olarak bu cinse aktarılmış olup, femurların dorsal ve ventralde iyi gelişmiş tepeciklere sahip olması, epimeral bölgesindeki ikincil kıllanmanın olması ve dört çift anal kıl taşıması ile ayırt edilmektedir (Paschoal 1986). Ayrica, Mahunka and Mahunka-Papp (1995) bu türe ait Berlese'nin koleksiyonunda bulunan 154/31 olarak işaretli tip serisinden incelediği örneğe dayanarak tamamlayıcı morfolojik karakterler vermiştir. Tüm bu veriler 1şığında incelediğimiz örneklerin türün bilinen özellikleri ile tam bir uyum içerisinde olduğu tespit edilmiştir.

\section{KAYNAKLAR}

Ayyıldız N., Toluk A., Taşkıran M. and Taşdemir A. 2011. Two New Records of the Genera Cepheus C.L. Koch, 1835 and Caleremaeus Berlese, 1910 (Acari: Oribatida) from Turkey, with Notes on Their Distribution and Ecology, Türkiye Entomoloji Bülteni, 1(3), 145-150.

Erman O., Özkan M., Ayyıldız N. and Doğan S. 2007. Checklist of the Mites (Arachnida: Acari) of Turkey. Second Supplement. Zootaxa, 1532, 1-21.

Mahunka S. and Mahunka-Papp L. 1995. The oribatid species described by Berlese (Acari). Hungarian Natural History Museum, Budapest, 325 pp.

Paschoal A.D. 1986. A Revision of the Plateremaeidae (Acari: Oribatei), Revista Brasileira de Zoologia, 3(6), 327-356.

Sitnikova L.G. 1975. A Revision of the Mites of the Family Cepheidae Berlese 1896 (Acarina, Oribatei) with Descriptions of New Species from the USSR. Entomologicheskoe Obozrenie, 54, 446-462.

Subías L. S. 2004. Listado Sistematico, Sinonimico y Biogeografico de los Acaros Oribatidos (Acariformes: Oribatida) del Mundo (Excepte fosiles). Graellsia, 60, 3 305 (actualizado en junio de 2006, en abril de 2007, en mayo de 2008, en abril de 2009 , en julio de 2010, en febrero de 2011, en abril de 2012, en mayo de 2013 y en febrero de 2014, en marzo de 2015 y en febrero de 2016) 
http://escalera.bio.ucm.es/usuarios/bba/cont/docs/RO_1.pdf. (Erişim tarihi: 26.2.2016).

Wissuwa J., Salamon J.A. and Frank T. 2013. Oribatida (Acari) in Grassy Arable Fallows Are More Affected by Soil Properties than Habitat Age and Plant Species. European Journal of Soil Biology, 59, 8-14. 
